\title{
Basic Income and the Problem of Cumulative Misfortune
}

\author{
Simon Wigley \\ Bilkent University (Turkey) \\ wigley@bilkent.edu.tr
}

(First Draft)

Paper for:

Basic Income European Network

$8^{\text {th }}$ BIEN Congress

'Economic Citizenship Rights for the $21^{\text {st }}$ Century'

Berlin, October 6-7 2000

At the heart of resource-egalitarianism lies a division of labour between the individual and society. (Scanlon, 1988, pp. 1997ff; Rawls, 1993, p. 189-190) In effect what this division amounts to is the apportioning of the consequences of good and ill luck. Thus, while in naturalistic terms an outcome may be beyond the control of the agent, they may still be said to bear responsibility for the outcome. Immediately this indicates that resource-egalitarianism does not, necessarily at least, rest on a voluntaristic account of responsibility. That is perhaps inevitable given that a naturalistic account only serves to shrink responsibility to vanishing 
point. (Nagel, 1982) Taken to its logical conclusion naturalism suggests that all outcomes are the responsibility of nobody in particular and therefore, if anything, the responsibility of society. Consequently, the cut-off point, the point at which the individual is said to be responsible, must appeal to an argument independent of the notion of control if it is to avoid arbitrarily attributing responsibility. Indeed as Arthur Ripstein points out, control is neither a sufficient or necessary component of responsibility. (Ripstein, 1994, pp. 12-13)

This does not of course mean that the idea of voluntariness is not employed. For it seems that we are motivated by the sense that 'the appropriateness of moral assessment is easily undermined by the discovery that the act or attribute, no matter how good or bad, is not under the person's control.' (Nagel, 1982, p. 175) Perhaps for that reason, the way we use the notion of responsibility will often appeal to the language of control. Indeed, liberal theorists appear to appeal to the minimal level of voluntariness implied by the idea of 'could have done otherwise' as a rough basis for dividing the responsibilities between society and the individual. Where an individual could not have done otherwise the outcome is something that has happened. Where they could have done otherwise then it is something they have done. Thus a distinction is made between where the agent had no choice in the matter (brute luck) and where they did have choices open to them (option luck) (Dworkin, 1981b, p. 293). In other words, society is allocated responsibility for those circumstances in which it was clearly not possible for the individual to avoid (natural and social advantages that individuals are born into). The individual is allocated responsibility for those 
outcomes where it is at least possible that they could be avoided (calculated gambles that individuals make in pursuit of what they value in life). In other words society's role is to rectify brute luck disadvantages and therefore enable the equal opportunity to choose. (Fleurbaey, 1995a, pp. 48-49) Because the division recognises that an individual cannot have full control over their ends they are said to bear rather than hold responsibility for them. (Fleurbaey, 1995a, pp. 44ff; Fleurbaey, 1995b, p. 684; Schaller, 1997, pp. 259-261) Moreover, a more finegrained assessment of causality would require an impractical level of information (Arneson, 1997), the investigation required by it would infringe on the individual's privacy (Fleurbaey, 1995a, pp. 49ff) and potentially impose values that the particular individual does not ascribe to (e.g. the individual's control over contributing to the social enterprise).

What I want to argue here is that the resource-egalitarian division of labour fails to achieve its avowed aim of prioritising the worst-off (ex post) and, more importantly, it does not provide an adequate means to choose in the first place (ex ante). The implications of this, I argue, is a further justification for an unconditional basic income and in particular its distribution as regular payments over each person's life-time rather than a one-off initial endowment at the age of majority.

\section{The Value of Choice}

In order to unpack the notion of choice that lies at the heart of the resourceegalitarian division of labour we may use T. M. Scanlon's discussion of the 
subject. (Scanlon, 1988;1998) By approaching the issue in this way I do not mean to say that Scanlon's account matches that of all other resourceegalitarians but rather that it provides a useful basis for exploring, in detail, the role of choice. Scanlon contends that people have positive reasons for '... wanting to have what happens depend on the way they respond when presented with alternatives under the right conditions.' (Scanlon, 1998, p. 251) In terms of instrumental value it increases the chances of the right choice being made. In terms of intrinsic value it shows others that the person was the one who chose (or did not choose) according to what they value in life and it respects individuals as capable of choosing. (Scanlon, 1998, p. 251ff) Consequently, the value of choice is undermined if we choose for the individual on the grounds that they are not competent enough or the values that lie behind their choices are supposedly not good for them. (Scanlon, 1998, pp. 254-256)

According to this account of responsibility, it is crucial to distinguish between the conditions for choosing and the choice that is actually made. If society provides individuals with the right conditions for choosing (if the value of choice is respected), then the latter is responsible for whatever choices they end up making. (Scanlon, 1998, p. 254). An individual takes responsibility for their choices if they had a fair opportunity to choose otherwise. (Scanlon, 1998, p. 286) The right choosing conditions requires:

(a) That there is a range of choices available such that the individual can avoid bad options and have access to good options. Significantly, the range of 
choices available to the individual is dependent on the extent of their internal and external resources. Brute luck disadvantage as a result of the circumstances a person is born with and into, is problematic only insofar as it denies the individual sufficient opportunity for choice. (Scanlon, 1988, pp. 187)

(b) That each individual has the opportunity to discern what is the best option. In other words they have ready access to all the relevant information regarding each option and the person is capable of choosing prudently ${ }^{1}$. (Scanlon, 1998, pp. 256ff)

Simply, providing the right conditions (i.e. respecting the value of choice) is sufficient for an individual to take responsibility irrespective of the degree of prudence and control in their choosing (e.g. ability to revise one's preferences in order to avoid a costly option, element of option luck in the ways things turn out etc). If a person's choosing under fair choosing conditions turns out to be harmful to them the idea is not necessarily that they should suffer that harm but rather that it is their problem. (Scanlon, 1998, pp. 293-294) Not having access to assistance for the harmful choices made under fair conditions is the necessary price we have to accept in order to ensure the value of choice. (Scanlon, 1988, pp. 200-201) Conversely, if the choosing conditions are not satisfied (e.g. if one's harmful choices are the result of the social conditions in which one is raised) then

\footnotetext{
${ }^{1}$ I.e. not addicted, drunk, suffering from grief, too young etc. The point is that the person is capable of choosing prudently rather than whether they do in fact choose prudently.
} 
the person should not be left to suffer the consequences of their choice (e.g. teenage pregnancy, crime, drug use etc). Society has a duty to assist if it has failed to provide the person with an adequate opportunity to avoid harmful choices. (Scanlon, 1998, pp. 292-293) Putting this in Scanlonian terms, if the right choosing conditions are in place then the individual cannot reasonably complain if their choice, as it were, goes wrong. (Scanlon, 1998, pp. 256-261). ${ }^{2}$

Take for example the case of paid employment (leaving aside the issue of unpaid but valuable work): according to the resourcist approach society should provide a fair opportunity to find employment (means to develop one's skills, reasonable job offers etc). If those conditions are not met (say there is no jobs available or those jobs that are available are underpaid, unsafe, unhygienic etc), then they are due assistance. Conversely, if the right job-choosing conditions are in place then it is the individuals problem if they find themselves without employment. Because this approach shuns any appeal to the control the individual has over their choosing it may be criticised on the grounds that it permits undeserved assistance and neglects those left in an undeserved predicament. On the one hand it might be too generous for, given say equilibrium unemployment, it leaves open the possibility that an individual can receive assistance without making any effort (i.e. free-ride on the productive efforts of others to the social enterprise). ${ }^{3}$ On the other hand it may be too callous given

\footnotetext{
${ }^{2}$ In other words, whether or not a person bears responsibility depends on whether they have reasonably grounds for complaint. They only have reasonable grounds for compliant if the right choosing conditions were not provided. What justifies and defines the right choosing conditions is those circumstances that are sensitive to the value of choice.

${ }^{3}$ See for example (White, 1997, pp. 317ff).
} 
that it leaves open the possibility that a victim of bad option luck is left to suffer the consequences.

The resourcist response to this is to point out that the cost to the value of choice entailed by a control-sensitive approach (over and above the impractical level of information that it would require) must outweigh our concern about freeriding and suffering. Consequently, it focuses on the opportunity to choose and disregards the outcomes that arise and the level of control that a person has over them. With regard to the problem of undeserved assistance I take this line of argument to be sound without further argument (that is if we accept free-riding as an concern in the first place); Establishing a standard of reciprocity and the extent to which it is voluntarily adhered to would be both intrusive and disregarding of the values held by each individual. But the problem of suffering, is more problematic. As Elizabeth Anderson has recently pointed out, we may ask whether those who are severely harmed by their choices under fair conditions should be left to suffer, irrespective of how prudent those choices were. (Anderson, 1999, p. 295ff) In effect she is challenging the justifiability of prioritising the ex ante worst-off and while not prioritising the ex post worst off.

A more serious challenge, however, concerns whether a fair opportunity to choose is provided by the resourcist division of labour in the first place. When we consider the phenomenon of choice from the point of view of a stream of gambles rather than a one-off gamble, it takes on the character of brute luck rather than option luck. A person's misfortune may accumulate entirely independently of the quality of their calculated gambles. If that is the case then 
society is obliged to rectify those who suffer harmful outcomes, not because of bad option luck or the harm per se, but because it has failed to provide a fair opportunity to choose otherwise.

\section{The Problem of Cumulative Misfortune}

When we consider a stream of gambles a person's absolute success may not even out and the timing and ordering of their failures is critical.

As the number of gambles in a person's life increases the proportion of successes will even out, but not necessarily the number of successes. For example, it still might be the case that after a large number of gambles, that the actual number of successes and failures between person $A$ and person $B$ are not the same. After 1000 gambles, suppose $A$ 's success rate was 0.509 , and therefore she has had 18 more successes than $B$. After 10000 gambles $A$ 's success rate may have reduced (although not necessarily) to 0.505 . $A$ would have been successful 100 more times than $B$ in spite of the lower success rate. Success has evened out as a proportion of the total, but not in terms of the actual or absolute outcomes. Person $A$ is only fractionally more successful than $B$ after 10000 gambles in terms of a proportion, and yet she has accrued a significantly greater number of successes. (Coram, 1998)

Even more significantly, life-chances are dependent on when, over a lifetime of calculated gambles, a person's failures occur. In the same way as it is possible that in making 100 coin tosses $80 \%$ of the first 10 are heads, one's initial sequence of calculated gambles may be predominantly failures. However, unlike 
coin tosses the starting point of each gamble is not (typically at least) replenished. One's subsequent ability to gamble is contingent on the success or failure (and impact) of the previous gamble. Thus if the initial series of gambles happen to be failures (even if the impact of each individually is minor) then (barring the unlikely event of a recuperative success of high magnitude) a person is already accumulating misfortune irrespective of how prudent their choices were. Hence, a person may be left in a position where their opportunity to choose is increasingly undermined.

The significance of an initial sequence of gambles suggests that one's life chances are more closely akin to brute luck rather than option luck. Over a lifetime of choices an individual can have no control over when and in what order option luck failures will occur. The fact that a series of failures (even if minor) occurs at the beginning of a life-time of choices is completely beyond the individual's control. Hence, there seems to be no difference between the occurrence of an initial sequence of option luck failures and the natural and social advantages that a person is born with. Both are entirely uncontrolled and both have a substantial influence on one's subsequent opportunity to choose. Taking this into account we may ask whether it is defensible to say that a person must just learn to live with the cumulative misfortune they have incurred.

Indeed it may be argued that the knock-on effect of choices undermines the entire resource-egalitarian account of responsibility. If because of prior bad option luck a person is no longer confronted by a fair opportunity to choose, then they cannot be said to be responsible for any choices they subsequently make. If 
that were the case society would be obligated to assist. However, I take it that resource egalitarians apply responsibility diachronically rather than to any particular moment. Thus the fact that a person through prudent or imprudent choices, ends up at some point in time with a deficient means to choose, it is their delegated responsibility. This point is illustrated by Ronald Dworkin claim that the envy test ${ }^{4}$ must be applied to a person's entire life rather than to any particular stage in it. (1981b, pp. 304ff) Given fair opportunity to choose a person cannot envy another person's resource position at a particular point in time if they failed to choose in the same way previously. They may envy the bundle of resources that a person has ended up with, but they cannot legitimately do so given that they could have made the same choices. According to the delegation of responsibility their envy of the bundle that another has is their problem.

But as we have seen the culmination of option bad luck severely strains the idea that the person can be taken as having control over a stream of calculated gambles. Two people with the same long-run intentions (i.e. same personal ends and life-plan), resources, and level of prudence may end up, over the stream of calculated gambles, in significantly different positions (i.e. in the extreme case one may experience a series of early failures while the other experiences a series of early successes). The culmination of option luck suggests that the person who ended up worse-off can legitimately envy the resource bundle of the person who ended up better-off. From this we can see that the envy-test is by no means a cut and dry basis for gauging equality. Rather

\footnotetext{
${ }^{4}$ A choice-based account of equality which claims that given the equal opportunity to choose otherwise, a person cannot envy another's bundle of resources. If they do then it is their
} 
it heavily depends on an argument as to what is entailed by 'could have chosen otherwise'. In other words, a market-based distribution of resources will fail the envy test as soon as it is contended that a prudent actor did not have a fair opportunity to avoid her predicament. Thus it is the account of responsibility that lies behind envy-freeness that is central. An account of responsibility that was more sensitive to control would expand the range of legitimate envy; Conversely a more libertarian reading of responsibility, one that delegates more to the individual, would shrink the range of legitimate envy. With this in mind it becomes clear that the envy test can be used to justify a broad range of distributive schemes. The idea of no-envy is, in itself, as helpful to us in determining principles of distributive justice as the idea of 'could have chosen otherwise'.

The problem, therefore, is that the cumulation of bad option luck amounts to bad brute luck and therefore effectively denies the possibility that the conditions for choice exist in the first place. That is to say it is opportunity inhibiting: As with brute luck natural and social disadvantages, societal assistance is required in order to ensure a fair opportunity to choose. Contrary to the view of Ackerman and Alstott, therefore, freedom is not always a gamble. (Ackerman \& Alstott, 1999, p. 43) We should be clear however, that root of the problem lies with providing a fair means to avoid harmful outcomes (i.e. the consequences of cumulative misfortune) rather than the need to compensate harmful outcomes per se. Thus, we must re-draw the resourcist cut in the following way: given fair choice conditions that take account of the problem of

responsibility in lieu of the fact that they chose wrongly. (Dworkin, 1981, pp. 285-287) 
cumulative misfortune, the individual is delegated responsibility for any harm that they incur.

\section{Regular Basic Income Payments}

What the problem of cumulative misfortune hints at is a non-paternalistic justification for regular payments of a unconditional basic income. A regularly paid basic income would partially replenish the ability of a person to take the next calculated gamble. A bad option luck sequence, therefore, would no longer inhibit a person's future opportunity to the same extent. The argument from cumulative misfortune provides a possible way to avoid the charge that regular payments of a basic income (as opposed to say a one-off lump sum at the age of majority (Ackerman and Alstott, 2000)) is overly paternalistic. Philippe Van Parijs has argued that the regular instalment approach is justified on the assumption that if we were 'in our right minds' we would wish to protect our old age years from the 'weakness of will' characteristic of our younger years. (Van Parijs, 1995, pp. 4748) A restriction of the choices available to people when they are younger is necessary in order to ensure our opportunity to choose when they are older. Our old age opportunity is protected against our youthful inability to fully take into account our quality of life when we are older. ${ }^{5}$ Elizabeth Anderson criticises this justification of instalments on grounds that it treats persons as not capable of making their own choices. (Anderson, 1999, p301) ${ }^{6}$

\footnotetext{
${ }^{5}$ Similarly, Ackerman and Aslott also appeal to the problem of 'failures in intrapersonal trusteeship' to justify mandatory social insurance. (1999, pp. 134-136)

${ }^{6}$ Note that Scanlon in his discussion of the value of choice appears to accept that the restriction of choice may in fact be a component of providing the right conditions for choice. Thus, for
} 
But if we view the order and timing of option luck failures as a matter of brute luck, then the issue is not whether we trust the individual to look after themselves (or their future selves), but of providing them with a fair means to (competently or incompetently) choose. Instalments are necessary in order to ensure a fair opportunity to choose throughout our lives and not just in old age. ${ }^{7}$ Nevertheless, the argument from cumulative misfortune does not completely avoid the charge of paternalism. A person who is granted the basic income as an initial lump sum has the option of dispersing its use over their life-time or privately insuring themselves against bad option luck. ${ }^{8}$ That paternalism may however be necessary given the fact that persons cannot be expected to fully take into account their concerns beyond a short term time-horizon.

The strongest case against an instalment-based approach is that a large initial payment is often necessary in order to initiate one's life-plan (e.g. university fees or business start-up costs etc). (Ackerman and Alstott, 1999, p. 35) ${ }^{9}$ Without that initial outlay each individual's ability to operate on a long-term basis is dependent on the resources they already have available to them (Ackerman and Alstott, 1999, p. 41-43). However, what this suggests is an initial lump sum in addition to regular basic income instalments. Those instalments remain necessary as a means to overcome cumulative misfortune and the myopia of our

\footnotetext{
example, society is obliged to fence-off an area of hazardous waste even when people have been provided with sufficient information in order to avoid the waste. (Scanlon, 1995, pp. 256ff)

7 This also gets around the charge that the instalment approach favours those who live longer. (Van Parijs, 1995, p.46)

${ }^{8}$ Elizabeth Anderson argues that private insurance is an inadequate solution on the grounds that a person may choose not to pay their premiums because they become destitute. (Anderson, 1999, p. 298) However, her argument neglects the fact that insurance pay-outs would protect the insuree against destitution due to bad option luck.
} 
youth. Ackerman and Alstott's strategy is to some extent similar: an initial lump sum complemented by a mandatory social insurance scheme as a safety net. (1999, chapter 8) In other words, an ex ante payment combined with ex post corrective in old age. It is not clear, however, how the social insurance would tackle the problem of cumulative misfortune (i.e. if for example their stake is undermined by a sequence of initial misfortunes), given that it is orientated to each person's circumstances later in their life rather than their opportunity throughout their life. Hence, If we take the problem of cumulative misfortune seriously a start-up grant and a regular basic income comprises a better strategy.

Moreover, once we combine the brute luck character of cumulative misfortune with our moral qualms with simply leaving people to (guiltily-e.g. not choosing insurance —or innocently) suffer, the case for regular basic income payments, I would contend, is further reinforced. For aside from the arguments from paternalism and fair opportunity, instalments can also be defended on the grounds that it assists the ex post worst-off. Regular and unconditional payments would mean that individuals are not simply left to suffer the consequences of their gambles. Thus, besides providing a fair opportunity to choose by countering bad brute luck it coincidently (at least partially) corrects harmful outcomes irrespective of prudence or control. However, that does not necessarily imply compensating the welfare deficiency resulting from choosing. Rather the harm incurred may be interpreted in terms of the opportunity lost by the worst-off. That is to say, the reason for and metric of compensation may be taken as the

\footnotetext{
${ }^{9}$ Ackerman and Alstott argue for an initial lump sum in complemented by a mandatory social insurance as a safety net. In other words, an ex ante payment combined with ex post corrective.
} 
opportunity denied, not the preference-satisfaction denied. ${ }^{10}$ In other words, regular basic income payments provide both a fair opportunity to choose ex ante and helps to restore that opportunity ex post. In effect the individual is not, in laissez faire fashion, delegated responsibility for all the harms they incur. And because a universal basic income does not look to fine-tune transfers according to control-based responsibility and/or welfare deficiency, the value of choice is not compromised.

In sum, regular payments of a basic income are justified once we re-think the appropriate delegation of responsibility between society and the individual. For reasons of paternalism (restricting choice when we are young in order to guarantee choice latter in life), fair opportunity (countering the brute luck implied by the problem of cumulative misfortune) and compensatory justice (restoring the opportunity to choose of the worst-off) society is obliged to provide a constant stream of basic income payments.

\section{References}

Ackerman, Bruce and Alstott, Anne. (1999) The Stakeholder Society, New Haven: Yale University Press.

Anderson, Elizabeth. (1999) 'What is the Point of Equality?' Ethics 109, pp. $287-$ 337.

\footnotetext{
${ }^{10}$ Compare this with the Richard Arneson's welfarist interpretation of the ex post aspect of basic income. (Arneson, 1992, pp. 509-510) See also (Van Parijs, 1995, p. 248. n. 30).
} 
Arneson, Richard. (1997) 'Egalitarianism and the Undeserving Poor' Journal of Political Philosophy, 5, pp. 327-350.

Arneson, Richard. (1992) 'Is Socialism Dead: A Comment on Market Socialism and Basic Income Capitalism', Ethics, 102, pp. 485-511.

Coram, B. Talbot. (1998) 'Why Social Scientists Should be Interested in Luck: A Note on Some Fallacies', Social Science Quarterly, 79, pp. 129-139.

Dworkin, Ronald. (1981) 'What is Equality? Part 2: Equality of Resources', Philosophy and Public Affairs, 10, pp. 283-345.

Fleurbaey, Marc. (1995a) 'Equal Opportunity or Equal Social Outcome?', Economics and Philosophy, 1, pp. 25-55.

Fleurbaey, Marc. (1995b) 'Equality and Responsibility', European Economic Review 39, pp. 683-689.

Nagel, Thomas. (1982) 'Moral Luck' in G. Watson ed. Free Will, New York: Oxford University Press.

Rawls, John. (1993) Political Liberalism (New York: Columbia University Press. Ripstein, Arthur. (1994) 'Equality, Luck and Responsibility', Philosophy and Public Affairs 23, pp. 3-23.

Scanlon, T. M. (1988) 'The Significance of Choice' in S. M. McMurrin ed. Tanner Lectures on Human Values Vol.VIII, Salt Lake City: University of Utah Press. pp. 149-216

Scanlon, T. M. (1998) What We Owe to Each Other Cambridge Mass.: Harvard University Press. 
Schaller, Walter E. (1997) 'Expensive Preferences and the Priority of Right: A Critique of Welfare Egalitarianism', Journal of Political Philosophy 5, pp. 254-273.

Van Parijs, Philippe. (1995) Real Freedom for All: What (if Anything) can Justify Capitalism? Oxford: Clarendon Press.

White, Stuart. (1997) 'Liberal Equality, Exploitation, and the Case for an Unconditional Basic Income', Political Studies, XLV, pp. 312-326. 